\title{
AS PRÁXIS INCLUSIVAS DE CRIANÇAS AUTISTAS NAS ESCOLAS DE EDUCAÇÃO INFANTIL
}

\section{ARTIGO DE REVISÃO}

OLIVEIRA, Aldeny Alves de ${ }^{1}$

OLIVEIRA, Aldeny Alves de. As práxis inclusivas de crianças autistas nas escolas de educação infantil. Revista Científica Multidisciplinar Núcleo do Conhecimento. Ano: 06, Ed. 08, Vol. 01, pp. 194-204. Agosto 2021. ISSN:24480959, Link de acesso: https://www.nucleodoconhecimento.com.br/educacao/aspraxis-inclusivas, DOI: 10.32749/nucleodoconhecimento.com.br/educacao/as-praxisinclusivas

\section{RESUMO}

O trabalho com crianças autistas na sociedade escolar, ainda necessita de muitas pesquisas, formação, investimento e informações para auxiliar os profissionais da área em atuação. A educação infantil é uma etapa importante para as crianças, propiciando condições para aprendizagem, desenvolvimento motor, troca interpessoal e promovendo diversidade entre os pares. Esta fase do desenvolvimento significa pensar nas possibilidades e práticas que conseguem envolver e despertar o interesse das crianças com transtorno do espectro do autismo na rotina escolar. A LDB enfatiza a melhor forma de receber o educando com necessidades especiais matriculados no ensino regular, visando um bom desenvolvimento pessoal e cognitivo. No Brasil a AMA é uma referência para os brasileiros com TEA, seus familiares, e pessoas direta ou indiretamente relacionadas a elas. Todas as crianças têm o direito, independentemente do seu problema e do

\footnotetext{
${ }^{1}$ Mestranda em Tecnologias Emergentes em Educação pela Must University. Especialização em Saneamento Ambiental pela FGF, Ludopedagogia e Educação Infantil pela UCAM, Especialização em Autismo em andamento pela Dom Alberto, Graduação em Ciências Biológicas pela UFMT e Pedagogia pela FAERPI.
}

RC: 93401

Disponível em: https://www.nucleodoconhecimento.com.br/educacao/as-praxis- 
estilo de aprendizagem, a escola. A inclusão escolar é um caminho importante para lidar com as diversidades impostas respeitando as limitações, características de todo ser humano, apostando na importância do conhecimento e no ensino dos diferentes estilos de prática e aprendizagem. O objetivo desta pesquisa bibliográfica é, relatar a importância da inclusão de crianças com diagnóstico de transtorno do espectro autista (TEA) na rotina escolar e as dificuldades que os educadores encontram na escola para o desenvolvimento destas crianças. A inclusão escolar de crianças com autismo na educação infantil vem acontecendo de forma gradual em todas as fases da educação. Os educadores e as práticas pedagógicas são a base para a concepção do trabalho com as crianças com TEA, auxiliando na solução das dificuldades impostas na sua vivência física, mental, emocional e social, sendo assim, o apoio da família é a base para que esse trabalho seja realizado com sucesso, trazendo benefícios para a criança, transformando-o em um cidadão capaz de ver o mundo conforme sua realidade. O TEA exigirá muitos estudos dos profissionais da educação para que possam aperfeiçoar os atendimentos, disponibilizando um trabalho com segurança e qualidade para a comunidade.

Palavra-Chave: inclusão escolar, educação infantil, educadores, autismo.

\section{INTRODUÇÃO}

O trabalho com crianças autistas na sociedade escolar, ainda necessita de muitas pesquisas, formação, investimento e informações para auxiliar os profissionais a desenvolverem um bom trabalho. O autismo faz parte de um grupo de síndromes neuropsiquiátricas formadas por doenças que afetam o desenvolvimento do cérebro. Segundo César (2015), cerca de 70 milhões de pessoas sofrem de transtorno do espectro do autismo (TEA), o que representa cerca de $1 \%$ da população. Percebese que o autista, tanto no ambiente social quanto no escolar, não tem recebido a devida atenção, para a ampliar suas capacidades cognitivas e superar suas dificuldades.

RC: 93401

Disponível em: https://www.nucleodoconhecimento.com.br/educacao/as-praxis- 
No Brasil, o governo estabeleceu políticas e diretrizes, proporcionando condições de ascensão ao espaço e recursos educacionais, habilitando os profissionais para alcançar a inclusão escolar no método de aprendizagem, avaliando as diferenças para atender à demanda dos educandos com atenção especializada. Essas políticas propicia a constituição de educadores especializados para formar essas crianças com deficiência, incentivando a interação da família na comunidade escolar.

A educação infantil é vista como espaço e tempo de aprendizagem, desenvolvimento motor, troca interpessoal e promoção da diversidade entre os pares, é uma etapa importante para as crianças. Nesta fase do desenvolvimento significa pensar nas possibilidades e práticas que conseguem envolver e despertar o interesse das crianças, principalmente crianças com transtorno do espectro do autismo. Assim todas as crianças têm o direito, independentemente do seu problema e dos estilos de aprendizagem que necessitam para aprender, a escola e os educadores promoverá e auxiliará no desenvolvimento. A inclusão é um caminho importante para lidar com a diversidade impostas respeitando as limitações, as características de todo ser humano, apostando na importância do conhecimento e no ensino dos diferentes estilos de prática e aprendizagem.

Deste modo busco alcançar ao longo dessa pesquisa, relatar a importância da inclusão de crianças com diagnóstico de transtorno do espectro do autismo (TEA) na rotina escolar, as dificuldades que os educadores passam na escola para proporcionar o desenvolvimento das crianças com autismo. A pesquisa bibliográfica serviu para apresentar definições sobre os principais conceitos, literatura de autores renomados e profissionais que tem se destacado no cenário global, como também utilização de revistas e sites especializados sobre o tema abordado. Abordando os temas "Inclusão", e o "Autismo" (TEA, Transtorno do Espectro do Autismo), em periódicos. Foram relacionando os artigos encontrados sobre o tema independente do ano de publicação. O levantamento foi realizado entre os dias 01 de novembro a

RC: 93401

Disponível em: https://www.nucleodoconhecimento.com.br/educacao/as-praxis- 
26 de fevereiro de 2021. Das publicações extraiu-se informações para o levantamento bibliográfico desta pesquisa.

\section{CARACTERIZAÇÃO E DEFINIÇÃO DO AUTISMO}

O autismo, cientificamente conhecido como transtorno do espectro autista, é uma síndrome caracterizada por problemas de comunicação, sociais e comportamentais, e geralmente é diagnosticada entre 2 e 3 anos de idade. Conforme com o Manual Diagnóstico e Estatístico de Transtornos Mentais (2014), o TEA é parte de uma doença específica de transtorno de aprendizagem, podendo ser reconhecido na primeira infância, afeta principalmente a comunicação e socialização dos indivíduos em diferentes níveis, dos mais leves aos mais graves.

Conforme Silva et al. (2012), propõem que precisa ser desfeito em dizer que o autismo só tem uma forma, existem muitas variações, algumas de forma claras á aquelas que não permite a conclusão de um diagnóstico preciso. Para Sousa e Santos (2014) a maioria das crianças com TEA demonstra rejeição ao contato físico, mas, como todos os aspectos relacionados a esta doença, isto não é uma regra, o que significa que algumas crianças podem não sentir esta situação de desconforto com o toque. Às vezes é quase imperceptível, podendo ser confundido com timidez, desatenção ou particularidades. O diagnóstico do autismo não é simples de se obter, é importante consultar um médico especializado para uma avaliação do desenvolvimento e do comportamento da criança e apontar um tratamento específico.

Utilizando os pensamentos de Silva et al. (2012) algumas crianças com autismo conseguem interagir socialmente com outras pessoas, mas, não são capazes de manter a interação por muito tempo, começam a brincar com outras crianças, logo deixa o grupo de lado e volta brincar sozinho. Existem algumas características típicas do autismo, como obsessão por objetos específicos, atenção aos detalhes, foco excessivos sobre o objeto, essas especificidades faz uma pessoa com espectro

RC: 93401

Disponível em: https://www.nucleodoconhecimento.com.br/educacao/as-praxis- 
do autismo tenha um bom desempenho em certas áreas cognitivas, essa função mental promove a hiperatividade de algumas áreas específica do cérebro, prejudicando outras.

Conforme Sousa e Santos (2014) à primeira vista, esse recurso parece ótimo, benéfico para as crianças, proporcionando o desenvolvimento em algumas suas áreas de interesse, contudo, outros aspectos da vida costumam sofrer, pois, as crianças optam por se concentrar apenas em suas áreas de interesse deixando as outras de lado. Dessa forma, o apoio da família é de grande valor, precisam focar nas áreas que apresentam maior dificuldade, especialmente na interação e socialização, para que haja um desenvolvimento integral em todos os campos cognitivos.

\subsection{AUTISMO NO BRASIL}

Para Sousa e Santos (2014) no Brasil existem muitas pessoas com TEA lutando por seus direitos, em 8 de agosto de 1983, foi quando surgiu a primeira organização de Assistência ao brasileiro com autismo, denominada Associação de Amigos do Autismo (AMA). Hoje, a AMA é considerada uma referência para os brasileiros com TEA, familiares, amigos e pessoas direta ou indiretamente relacionadas a ela. No entanto, existe outra instituição no Brasil, a Associação Brasileira de Autismo (ABRA), entidade nacional responsável por reunir todas as associações de pais e amigos de brasileiros com autismo.

De acordo com informações da Organização Mundial da Saúde, as Nações Unidas estabeleceram o "Dia Mundial da Conscientização do Autismo" em 2 de abril, para chamar a atenção do público em geral para a importância de compreender e tratar esta doença, que afeta milhões de pessoas. Em 2012 foi aprovada a "Lei Berenice Piana" (12.764 / 12), que institui a "Política Nacional de Proteção aos Direitos das Pessoas com Transtorno do Espectro do Autismo", este arcabouço é relevante para proteger os direitos dos pacientes autistas, estabelecendo um sistema único de

RC: 93401

Disponível em: https://www.nucleodoconhecimento.com.br/educacao/as-praxis- 
saúde com o intuito de obter diagnóstico precoce, tratamento, terapia, medicamentos, educação, proteção social, igualdade, oportunidades de trabalho e serviços.

Agora, o DSM-5 (MANUAL DIAGNÓSTICO E ESTATÍSTICO DE TRANSTORNOS MENTAIS, 2014), inclui todas as subcategorias de autismo em um único diagnóstico, os indivíduos são diagnosticados com base em um único espectro de gravidade variável, é definido por dois critérios: déficits sociais e de comunicação e a presença de comportamentos repetitivos e estereotipados.

A Lei Brasileira de Inclusão da Pessoa com Deficiência (13.146/15), cria o Estatuto da Pessoa com Deficiência, aumentando a proteção dos portadores de TEA definindo as pessoas com deficiência "aquela que tem impedimento de longo prazo de natureza física, mental, intelectual ou sensorial”. O Estatuto é um símbolo importante na defesa da igualdade de direitos dos deficientes, no combate à discriminação e da regulamentação da acessibilidade e do atendimento prioritário.

\section{A INCLUSÃO ESCOLAR DOS EDUCANDOS COM TEA}

No dia 20 de dezembro de 1996, foi criada as Diretrizes e Lei Básica da Educação Nacional (LDB) $\mathrm{n}$-9.394, com o intuito de enfatizar a melhor forma de receber os educandos com necessidades especiais, que encontram matriculados nas fases do ensino regular de submeter para dar um bom atendimento com visando a possibilidade de um bom desenvolvimento pessoal e cognitivo. Assim o sistema educacional deve garantir que esses educandos tenham currículos, metodologias, técnicas especializadas e recursos educacionais para suprir suas necessidades escolares. Como Bernardino (2015) frisa que é importante valorizar esses educandos em seus paradigmas, dificuldades e o real desenvolvimento de vida, concernente às suas desconformidades.

RC: 93401

Disponível em: https://www.nucleodoconhecimento.com.br/educacao/as-praxis- 
Em 27 de dezembro de 2012, foi sancionada a Lei $n^{0}$ 12.764, que formulou uma política nacional de proteção aos direitos do paciente autista, garantindo a educação e a formação profissional para o paciente autista e incentivando-o a realizar treinamentos e capacitações profissionais especializadas. Conforme Caneda e Chaves (2015), a lei também prevê companhia especial para educandos com autismo incluídos no ensino formal. Kupfer (2005) relata que dificilmente os educandos com autismo integram a escola devido a aceitação das intervenções externas.

Serra (2010) apontou a existência de mediadores e conselheiros para auxiliar os educadores no método de integração dos autista, assim, o papel do educador é auxiliar o educando nas atividades propostas, incentivá-los a participar de atividades comuns a toda a turma, proporcionar atividades paralelas quando impossível, mudar o ambiente se for possível para beneficiar o bem estar, assim, o educador é considerado uma ponte entre a relação social e o educando com e os demais colegas e ambientes da escola. Para Amâncio e Assali (2005), é importante abrir mão dos manuais de ensino e psicologia, visando uma educação homogênea para que o método de integração não seja prejudicado.

Dessa forma, as escolas devem ter em seu projeto político pedagógico os benefícios e propostas que serão desenvolvidas com os educandos, não esquecendo da participação da família neste momento é de grande importância para a realização dos trabalhos. Atualmente os profissionais que atuam estão preparados com qualificação adequada para receber esses alunos com TEA, algumas escolas foram implantadas salas do AEE, com recursos especializado para atender a demanda e necessidade da comunidade, os atendimentos é diferenciado voltado somente para a criança naquele momento, esse atendimento diferenciado é ofertado no contraturno do horário da regular que o educando cursa, esse trabalho é realizado por educadores especializados.

RC: 93401

Disponível em: https://www.nucleodoconhecimento.com.br/educacao/as-praxis- 
Mesmo com as formações e sendo especialistas na área da inclusão, percebe-se que existe muitas dificuldades a serem sanadas, cada educando apresenta suas especificidades e limitações exigindo do educador estudos e estratégias para obter atenção e fazer com que esses educandos consigam superar suas limitações, adquirindo conhecimento e autonomia para o desenvolvimento de uma vida normal.

\subsection{O DESAFIO DO EDUCADOR DIANTE DE EDUCANDOS COM TEA}

O papel do educador é essencial na educação inclusiva pois é a autoridade competente para orientar o método de aprendizagem, intervir e criar condições necessária para apropriação indébita do conhecimento, dessa forma Freire relata que (2005, p. 58), “o ideal é que na experiência educativa, educandos, educadoras e educadores, juntos 'convivam' de tal maneira com os saberes que vão virando sabedoria. Algo que não é estranho a educadores e educadoras".

Segundo Mantoan (1997, p. 120), a inclusão é a razão da modernização escolar, aprimoramento das práticas e melhoria na atuação de educadores, assim, "a inclusão escolar de pessoas deficientes torna-se uma consequência natural de todo um esforço de atualização e de reestruturação das condições atuais do ensino básico". Promovendo um ensino igualitário, sem desigualdade, quando tratarmos de inclusão, não estamos falando apenas de pessoas com deficiência, mas também de uma escola que destaca sua singularidade e diversidade, formando um cidadão para a sociedade.

O educador precisa reconsiderar sua estratégia de ensino para evitar problemas, no espaço delineado em sala de aula, é necessário reconsiderar a prática docente considerando não só o meio, mas também a mobilidade e a durabilidade no espaço. Para Mantoan (2009, apud SOARES; FIGUEIREDO, 2007, p. 142), "compreender o espaço que cada um está inserido é compreender uma gama de possibilidades partindo da prática educativa dos professores".

RC: 93401

Disponível em: https://www.nucleodoconhecimento.com.br/educacao/as-praxis- 
Conforme a Resolução CNE / CEB nº 02/2001, a educação especial oferece suporte e fornece serviços profissionais para educandos com necessidades educacionais especiais. Um dos problemas, é a formação dos professores, a carência de disciplinas específicas sobre o tema da educação inclusiva. São poucas as graduações que ministram disciplinas relacionadas ao tema. Portanto, muitos educadores, não estão preparados para enfrentar situações que exigem alfabetização e ensino especial do aluno. Assim, é necessário que os profissionais que atuam na educação inclusiva busquem novos conhecimentos por meio da educação continuada, pós-graduação e outros.

Educadores considerados qualificados para trabalhar nas classes normais e com educandos com necessidades educacionais especiais, devem estar incluídos em seu nível intermediário ou superior de educação especial adequado para desenvolvimento com habilidades na área do conhecimento para necessidades especiais.

\section{TEA NA EDUCAÇÃO INFANTIL}

Conforme Gomes (2007, p. 346) ressalta que o educador deve estar atento ao planejamento docente para que as crianças com autismo possam responder aos estímulos ambientais, às formas de pensar e seus comportamentos típicos que apresentam. Ainda com pensamentos de Gomes (2007) [...] "a imaginação e a brincadeira simbólica, são fundamentais para a apreensão de conceitos emblemáticos acadêmicos, são restritos e até mesmo ausentes. Dificilmente veremos uma criança autista brincando de faz-de-conta". Dessa forma podemos visualizá-lo por várias horas, explorando um objeto, empilhado ou alinhado peças de encaixe, mas se a criança participar de uma sala regular na educação infantil, com estímulos e observação durante as brincadeiras, o mesmo pode desperta interesse pela brincadeira, como já pôde ser visto na prática uma criança brincando no parque de areia, na dança da cadeira entre outras, mesmo que a criança com autismo

RC: 93401

Disponível em: https://www.nucleodoconhecimento.com.br/educacao/as-praxis- 
apresenta dificuldade em compreender estímulos auditivos e conceitos abstratos, é necessário que o educador use linguagem objetiva.

A elaboração de um plano de educação personalizado (PEI), essa ferramenta visa planejar e monitorar o desenvolvimento das crianças com dificuldades de aprendizagem com base nas diretrizes da escola. O PEI tem como desígnio nortear o trabalho da escola para dar prioridade aos educandos que precisam de adaptação curricular, todos os campos de desenvolvimento do educando precisam ser abordados.

Ao planejar o ensino de crianças autistas, o espaço físico da sala de aula deve ser considerado, arrumar os móveis da sala pode ajudar ou atrapalhar o funcionamento independente das crianças, reconhecer e respeitar as regras e restrições. Ao planejar a estrutura física da sala de aula, não se pode esquecer das dificuldades dos educandos autistas, muitos têm dificuldades de organização pessoal, não sabem para onde ir e como chegar da forma mais fácil, é difícil aceitar a linguagem, eles geralmente não aprendem instruções ou regras. A utilização de imagens como meio alternativo de comunicação, é uma forma importante de proporcionar a comunicação entre os educandos com TEA, dessa forma a criança poderá usá-las para comunicar-se.

Cunha (2012, p. 30) adverte que sempre "haverá conquistas e erros, muitas vezes mais erros do que conquistas, mas o trabalho jamais será em vão". O educador sempre estará à frente com a equipe pedagógica escolar e a família trabalhando para que essa criança receba da melhor forma possível, o conhecimento para o desenvolvimento de todos os aspectos cognitivos.

Conforme Bibiano (2011), Rodrigues e Santos (2016), os administradores estão preocupados em buscar recursos e pessoal qualificado para a melhoria das condições de trabalho dos educadores, a fim de cooperar com o atendimento e com Sistema de Educação Profissional (AEE), com diferentes recursos técnicos,

RC: 93401

Disponível em: https://www.nucleodoconhecimento.com.br/educacao/as-praxis- 
contribuindo para a performance do educando. Assim, a escola deve tentar adequar sua infraestrutura, recursos e na preparação dos profissionais para buscar soluções conjuntas com especialistas e familiares, fornecendo aos educadores da educação especial (AEE) a formação continuada implantando cursos específicos sobre o Autismo (TEA), disponibilizando recurso para melhor atendê-los.

\section{CONCLUSÃO}

Por meio desta pesquisa, verificamos que a inclusão escolar vem acontecendo de forma gradual em todas as fases da educação, a participação da família é de grande importância para que a relação escolar aconteça de forma tranquila para a criança autista. A vivência, a socialização e o espaço familiar são de grande importância, a concepção de parcerias educativas na relação escola-família visando a promoção do desenvolvimento integral das crianças.

$\mathrm{Na}$ inclusão das crianças com autismo na educação infantil, os educadores usam vários métodos para explorar a interação e o potencial educacional dessas crianças, ponderando o bom senso da organização dos espaços, da interação e do andamento do ensino para obter um resultado no desenvolvimento das crianças. Através de muitas iniciativas e persistências, o autismo é compreendido e aceito na sociedade, tornando mais inclusivo e afeiçoado, tratando-se de uma troca realista de uma aparência sensível e de passos para um mundo diversificado, sem preconceitos e imposição aos outros. Dessa forma, o olhar do educador deve estar voltado para o ambiente escolar, no qual deve acolher as crianças de forma integral, atentos ao seu potencial e não às suas dificuldades.

O educador e as práticas pedagógicas desenvolvidas devem ser a base para a concepção e realização desse trabalho, conduzindo não apenas a superação das barreiras, mas focado num olhar para além da escola, dessa forma, essa visão expande a ação tornando-a significativa e deleitosa. Não esquecendo que a família é a base para que todo esse trabalho seja realizado com sucesso, trazendo benefícios

RC: 93401

Disponível em: https://www.nucleodoconhecimento.com.br/educacao/as-praxis- 
para a criança, transformando-o em um cidadão capaz de ver o mundo conforme sua realidade, dissipando as dificuldades impostas na sua vivência física, mental, emocional e social.

Como podemos observar, o TEA exigirá muitos estudos para que os profissionais da educação possam melhorar os atendimentos, oferecendo um trabalho com mais segurança, qualidade para atender as crianças com TEA que são muito inteligentes, só precisamos encontrar uma forma específica para acessá-los de forma correta. Dessa forma, futuras pesquisas podem ser abordadas com uma crítica mais profunda, proporcionando aos pesquisadores maiores conhecimentos sobre área, fortalecendo assim o movimento da inclusão escolar e do autismo.

\section{REFERÊNCIAS}

AMÂNCIO, V.; ASSALI, A. M. O saber e o não saber - do crer ao criar: eis uma das questões na escolarização de crianças psicóticas - duas histórias de travessias pelo Ponte. In: COLLI, F. A. G.; KUPFER, M. C. M. (Orgs.). Travessias inclusão escolar: a experiência do grupo ponte Pré-escola Terapêutica Lugar de Vida. (p.73-85), São Paulo, SP: Casa do Psicólogo, 2005.

AMERICAN PSYCHIATRIC ASSOCIATION - APA. Manual diagnóstico e estatístico de transtornos mentais: DSM-5. Porto Alegre: Artmed, 2014.

BERNARDINO, L. M. F. A importância da escrita na clínica do autismo. Estilos da Clínica: Revista sobre a Infância com Problemas, 20 (3), (p. 504-519), São Paulo, SP: USP - Instituto de Psicologia, 2015.

BIBIANO, B. Inclusão. Revista Nova Escola, Rio de Janeiro, n. 244, p. 48-55, 2011.

BRASIL. Lei no 12.764, de 27 de dezembro de 2012. Política Nacional de Proteção dos Direitos da Pessoa com Transtorno do Espectro Autista. Brasília, DF, 2012.

RC: 93401

Disponível em: https://www.nucleodoconhecimento.com.br/educacao/as-praxis- 
Disponível

em:

<http://www.planalto.gov.br/ccivil_03/_ato20112014/2012/lei//12764.htm>. Acessado em: 26 de março de 2021.

BRASIL. Lei no 13.145, de 6 de julho de 2015. Lei Brasileira de Inclusão da Pessoa com Deficiência (Estatuto da pessoa com deficiência). Disponível em: <http://www.planalto.gov.br/ccivil_03/_ato2015-2018/2015/lei//13146.htm>. Acesso em 21/11/2020.

BRASIL. Lei no 9.394, de 20 de dezembro de 1996. Secretaria de Educação Especial - MEC, SEESP. Brasília, DF, 1996. Disponível em: <http://www.planalto.gov.br/ccivil_03/leis/19394.htm>. Acesso em: 26/03/2021.

BRASIL. Ministério da Educação. Saberes e práticas da Inclusão. Secretaria de Educação $\quad 2006 . \quad$ Dspecial, 2 em: $<$ http://portal.mec.gov.br/seesp/arquivos/pdf/alunosdeficienciafisica.pdf>. Acesso em: 12/12/2020.

CÉSAR, M. Autismo afeta cerca de $1 \%$ da população. SES - Secretaria de Estado de Saúde de Minas Gerais, 4:46, abril 2015. Disponível em: $<$ https://www.saude.mg.gov.br/ajuda/story/6884-autismo-afeta-cerca-de-1-da->. Acesso em: 26/01/2021.

CONSELHO NACIONAL DE EDUCAÇÃO CÂMARA DE EDUCAÇÃO BÁSICA. Resolução CNE/CEB № 2, de 11 de fevereiro de 2001. Disponível em: <http://portal.mec.gov.br/seesp/arquivos/pdf/res2_b.pdf>. Acesso em: 20/12/2020.

CUNHA, E. Autismo e inclusão: psicopedagogia e práticas educativas na escola e na família. 4 ed. Rio de Janeiro: Wak, 2012.

FREIRE, P. Pedagogia da autonomia: saberes necessários à prática educativa. 13, ed. São Paulo: Paz e Terra, 2005.

RC: 93401

Disponível em: https://www.nucleodoconhecimento.com.br/educacao/as-praxis- 
GOMES, N. L. Educação e diversidade cultural: refletindo sobre as diferentes presenças na escola. 1999. Disponível em: <https://docplayer.com.br/10164896Educacao-e-diversidade-cultural-refletindo-sobre-as-diferentes-presencas-naescola.html>. Acesso em: 12/12/2020.

KUPFER, M. C. M. Inclusão social: a igualdade e a diferença vistas pela psicanálise. In: COLLI, F. A. G.; KUPFER, M. C. M. (Orgs.). Travessias inclusão escolar: a experiência do grupo ponte Pré-escola Terapêutica Lugar de Vida. (p.17-28). São Paulo, SP: Casa do Psicólogo, 2005.

MANTOAN, M. T. E. (Org.). A integração de Pessoas com Deficiência: contribuições para uma reflexão sobre o tema. São Paulo: Memnon, Editora Senac, p. 57-61, 1997.

RODRIGUES; K. do E. S.; SANTOS, M. F. R. Crianças autistas: procedimentos metodológicos a favor da inclusão escolar. Disponível em: $<$ https://portal.fslf.edu.br/wp-content/uploads/2016/12/tcc_05.pdf>. Acesso em: 04/01/2021.

SERRA, D. Sobre a inclusão de alunos com autismo na escola regular. Revista de Psicologia, 1 (2), 163-176, 2010.

SILVA, A. B. B.; et al. Mundo singular: entenda o autismo. Fontana, 2012. Disponível em: <http://www.repositorio.ufc.br/bitstream/riufc/33717/1/2017_dis_gomesgb.pdf>. Acesso em: 12/12/2020.

SOUSA, P. M. L.; SANTOS, I. M. S. C. Caracterização da síndrome autista. novembro 2014. <https://www.psicologia.pt/artigos/textos/A0259.pdf>. Acessado em: 12/12/2020.

Enviado: Março, 2021.

RC: 93401

Disponível em: https://www.nucleodoconhecimento.com.br/educacao/as-praxis- 
Aprovado: Agosto, 2021.

RC: 93401

Disponível em: https://www.nucleodoconhecimento.com.br/educacao/as-praxisinclusivas 